\title{
Tendências e Perspectivas da Produçáo Acadêmica Sobre a Temática Educação de Surdos: Mapeamento da Produçáo ${ }^{1}$ Tendencies and Perspectives of Academic Production on the Theme of DEAF EDUCATION: MAPPING PRODUCTIONS
}

\author{
Denise Marina RAMOS ${ }^{2}$ \\ Leandro Osni ZANIOLO ${ }^{3}$
}

\begin{abstract}
RESUMO: este estudo objetivou apresentar algumas tendências e perspectivas da produção acadêmica referente à temática educação de surdos, considerando-se as teses e dissertaçóes constantes no Banco de Teses da CAPES segundo o ASSUNTO Educação de surdos e ANO BASE 2005 a 2009. Constituiu-se em uma investigação de caráter exploratório descritivo e de natureza bibliográfica. Por meio das informaçôes bibliográficas e com base nos resumos das produçôes acadêmicas, pretendeu-se, a partir da catalogação dos dados, mapear o respectivo campo do conhecimento. Os dados coletados permitiram observar a distribuição anual e por modalidade da produção acadêmica, a distribuição geográfica e segundo as universidades, os níveis de financiamento e os programas de pós-graduação aos quais está vinculada essa produção. Os resultados obtidos corroboram os apontamentos de estudos que focalizaram semelhantes aspectos, como o crescimento constante no número de Mestrados e Doutorados no país, a prevalência de produçôes na modalidade Mestrado acadêmico, a distribuição geográfica e institucional dos estudos concentrada nas regióes Sudeste e Sul e a insuficiência de aportes financeiros, por meio da concessão de bolsas de estudos, destinados à produção científica. Ressalta-se também, o percentual expressivo de instituiçóes privadas, a prevalência de estudos vinculados a programas em Educação, Letras e Linguística, bem como, a presença de programas comumente observados em diferentes áreas de investigação, como programas em Ciência da computação, Engenharia e Tecnologia. Por fim, evidencia-se a relevância de estudos que visem sistematizar e inventariar a produção acadêmico-científica em um determinado campo do conhecimento, contribuindo para o aprimoramento da área e de seus objetos de investigação.
\end{abstract}

PALAVRAS-CHAVE: Educação Especial. Educação dos Surdos. Produção Científica. Sistematização do Conhecimento.

\begin{abstract}
This study aimed to present some tendencies and perspectives of academic research production related to the theme of deaf education, considering dissertations and theses contained in the CAPES Database according to the SUBJECT Deaf education and YEAR 2005 to 2009. An exploratory investigation of descriptive and bibliographical nature was carried out. Using bibliographic information and academic productions abstracts, the aim was to catalogue relevant information and map this field of knowledge. The collected data enabled us to observe the yearly distribution according to the mode of academic production, the geographical distribution, according to location of public and private universities, funding levels and the graduate programs responsible for the production. The results corroborate the results from other studies that focused on similar aspects, such as the steady growth in the number of Masters' and Doctoral studies in the country, the prevalence of productions at the Masters' level, the geographical distribution and institutional studies concentrated in the Southeast and Southern regions, and the insufficient level of funding, by means of grants and scholarships for scientific production. The study showed the involvement of a significant percentage of private institutions, the prevalence of studies related to Education, Language and Literature, and Linguistics programs, as well as the presence of programs commonly observed in diverse areas of investigation, such as Computer Science, Engineering and Technology programs. Finally, the study underscores the importance of studies aiming to organize and inventory the academic and scientific production in a specific field of knowledge, contributing to advancing the area and its research objects.
\end{abstract}

KEYWORDS: Special Education. Education of the Deaf. Scientific Production. Systematization of Knowledge.

\footnotetext{
${ }^{1}$ Subvenção: Bolsa Mestrado CAPES

${ }^{2}$ Mestre pelo Programa de Pós-Graduação em Educação Escolar - FCL-UNESP/CAr e Doutoranda no Programa de Pós-Graduação em Educação Especial da Universidade Federal de São Carlos. São Carlos, SP, Brasil. denise.m.ramos1@gmail.com.

${ }^{3}$ Professor Assistente Doutor II na Universidade Estadual Paulista Júlio de Mesquita Filho - Faculdade de Ciências e Letras - Departamento de Psicologia da Educação e Programa de Pós-Graduação em Educação Escolar. Araraquara, SP, Brasil.

zaniolo@fclar.unesp.br.
} 


\section{INTRODUÇÁo}

De acordo com Ferreira (2002), nos últimos anos tem se produzido um conjunto significativo de estudos conhecidos pela denominação de estado da arte ou estado do conhecimento. Definidos como de caráter bibliográfico, esses estudos apresentam em comum o desafio de mapear e de discutir certa produção em diferentes campos do conhecimento, investigando os aspectos e dimensões que vêm sendo destacados e privilegiados em diferentes épocas e lugares, as formas e as condiçôes em que têm sido produzidas certas teses e dissertaçôes, publicaçôes em periódicos e comunicaçóes em anais de congressos e de seminários.

Realizar um estudo dessa natureza justifica-se, como ratifica André (2001), pelo interesse em rever e analisar criticamente o que vem sendo produzido em determinada área do conhecimento a fim de buscar caminhos para seu contínuo aprimoramento.

Considerando-se que a educação de surdos foi historicamente concebida e vem sendo narrada nas atuais políticas educacionais como uma modalidade da Educação Especial (KLEIN; FORMOZO, 2009), faz-se pertinente discorrer acerca da pesquisa em Educação Especial no Brasil, dado o seu papel na produção de pesquisas em educação de surdos.

Segundo Nunes et al. (1998), a produção científica em Educação Especial obteve maior impulso a partir do final da década de 1970 quando foram criados o Programa de Mestrado em Educaçấo Especial da Universidade Federal de São Carlos (PPGEEs/UFSCar) e o Curso de Mestrado em Educação da Universidade do Estado do Rio de Janeiro (CMEd/UERJ), com uma área de concentração, e posteriormente, linha de pesquisa em Educação Especial. De acordo com os autores, o crescimento da Educaçáo Especial enquanto área de conhecimento apresentou-se constante, sendo desenvolvida em diversas instituiçóes como projeto, linha de pesquisa ou mesmo área.

Diversas pesquisas têm apresentado importantes contribuiçóes ao analisarem as tendências da produção acadêmica em Educação Especial, assim como os estudos desenvolvidos por Nunes et al. (1998), Bueno (2008) e Manzini (2011), apresentados a seguir.

Nunes et al. (1998), desenvolveram um projeto de pesquisa com o intuito de caracterizar o PPGEEs/UFSCar e a área de Educação Especial do CMEd/UERJ, bem como, proceder a uma análise crítica da produção discente desses programas. Foram analisadas 210 dissertaçóes, referente ao período de 1981 (ano da primeira defesa) a 1995 na UFSCar e 1982 (ano da primeira defesa) a 1997 na UERJ. Ressalta-se que na ocasião do desenvolvimento da pesquisa, a UERJ e a UFSCar mantinham apenas curso de pós-graduação em nível de mestrado.

A análise crítica das dissertaçôes produzidas nos respectivos programas desenvolveuse a partir da organização, classificação e articulação dos objetos de estudo (temas), referencial teórico, métodos, resultados e recomendaçōes (NUNES et al., 1998).

No trabalho intitulado Pesquisa em Educação Especial na Pós-graduação (NUNES et al., 1998), apresentam-se os temas predominantes nos estudos analisados, como ensinoaprendizagem; formaçâo e capacitaçáo de recursos humanos; atitudes e percepçôes de pais e profissionais; identificação e caracterização; integração; profissionalização; e auto percepção da pessoa especial. 
As autoras evidenciam também, a prevalência de enfoques socioculturais nos estudos a partir de aportes teóricos da Psicologia Social, Antropologia e Sociologia, bem como, assinalam a escassez de estudos referentes aos aspectos históricos da Educação Especial e de sua contextualização no quadro geral da Educação no país.

Esse aspecto foi igualmente ressaltado por Bueno (2008) ao realizar um balanço da produção acadêmica, constante no Banco de Teses da CAPES, segundo os descritores inclusão escolar e educação inclusiva referente ao período de 1997 a 2003.

Bueno (2008) assinala ainda, para a necessidade de um diálogo mais intenso entre as pesquisas na área de Educação Especial com outras áreas de investigação, como a de educação de jovens e adultos, estudos sobre escolarização e desigualdades sociais, bem como, entre as esferas institucionais e os programas de pós-graduação.

$\mathrm{O}$ autor destaca o número significativo de produçóes acadêmicas acerca da temática investigada e a diversidade de temas enfocados, como docência; organização do trabalho escolar; política educacional/social; alunado; história da Educação Especial; produção científica em Educação Especial; relação escola-comunidade e relação saúde-educação. Todavia, de acordo com Bueno (2008), "Se não mantivermos constante diálogo com essas produçóes, corremos o risco de estarmos continuamente reiterando estudos semelhantes.” (BUENO, 2008, p.44).

Bueno (2008) evidencia também, a imprecisão das informaçóes contidas nos resumos das teses e dissertações analisadas, aspecto igualmente observado em outros balanços realizados pelo autor, como no estudo que compreendeu a produção acadêmica acerca das temáticas inclusão escolar e educação inclusiva referente ao período de 1981 a 1998 (BUENO, 2005).

Manzini (2011) analisou a qualidade e o tipo de conhecimento produzido em Educação Especial frente à metodologia empregada nas dissertaçóes e teses financiadas pelo Programa de Apoio a Educação Especial (PROESP), referente ao período de 2004 a 2008.

Os estudos foram organizados e analisados a partir de cinco categorias: pesquisas que apresentavam generalização e aplicação imediata dos resultados (10 produçôes); pesquisas que apresentavam resultados imediatos para um grupo específico de participantes (oito produçóes); pesquisas descritivas com achados inovadores (quatro produçóes); pesquisas de intervenção com achados inovadores (três produçóes); e pesquisas descritivas que corroboram outras pesquisas (duas produçóes) (MANZINI, 2011).

De acordo com o autor, os estudos analisados, em sua maioria, produziram conhecimentos passíveis de serem aplicados imediatamente para a população a que se destina a inclusão. Evidencia-se a necessidade de avançar em metodologias pouco utilizadas na área de educaçáo, como análise estatística, metodologias inovadoras e de alta tecnologia, bem como, a interface entre a educação e outras áreas e disciplinas, contribuindo para o avanço temático e metodológico dos estudos.

Os estudos citados, embora contemplem diferentes enfoques, evidenciam importantes questóes acerca da pesquisa em Educação Especial no Brasil. Os estudos permitem traçar um panorama histórico da produçáo acadêmica na área, identificando-se tendências, perspectivas e lacunas no conhecimento produzido, no sentido de contribuir para o aprimoramento desse 
campo de investigação, bem como, paras as transformações na prática cotidiana da Educação Especial.

No rastro dessa discussão, o presente artigo objetivou apresentar algumas tendências e perspectivas da produção acadêmica referente à temática educação de surdos, considerando-se as teses e dissertaçóes constantes no Banco de Teses da CAPES segundo o ASSUNTO Educação de surdos e ANO BASE 2005 a 2009, mapeando o respectivo campo do conhecimento segundo os indicadores: ano, modalidade, órgãos de fomento, estados brasileiros, universidades e programas de pós-graduação stricto sensu.

Vale ressaltar que esse artigo constitui-se em um recorte de dissertação de mestrado desenvolvida no contexto do Programa de Pós-graduação em Educação Escolar, na Universidade Estadual Paulista “Júlio de Mesquita Filho" - Faculdade de Ciências e Letras de Araraquara.

\section{Método}

Para se estabelecer o referencial metodológico desse estudo, a nomenclatura proposta por Vilelas (2009) foi empregada a fim de fornecer seus fundamentos. Neste sentido, o presente estudo constitui-se em uma investigação de caráter exploratório descritivo e de natureza bibliográfica.

Primeiramente, definiu-se o Banco de Teses da CAPES como locus para a coleta de dados desse estudo, dado o papel que desempenha a CAPES para a consolidação e expansão da pós-graduação stricto sensu no país e, sobretudo, o caráter único do Banco de Teses da CAPES no acesso e divulgação da produção científica em âmbito nacional.

Em seguida, realizou-se um levantamento exploratório no Banco de Teses da CAPES a partir dos campos ASSUNTO (todas as palavras) e ANO BASE, utilizando-se os descritores: Surdez, Educação de surdos, Inclusão de surdos, Lingua Brasileira de Sinais (LIBRAS) e Identidade surda, segundo os anos de 2000 a 2009, a fim de observar a incidência da produção acadêmica por ASSUNTO e ANO BASE, bem como, definir o descritor de busca e o recorte temporal do presente estudo. Tais descritores foram selecionados dada a relevância nas discussóes atuais desse campo do conhecimento, bem como, a perspectiva teórica desse estudo. Ressalta-se que a produção acadêmica referente ao ANO BASE 2010 não constava no Banco de Teses da CAPES no período que compreendeu a coleta de dados.

Considerando-se que o objeto de investigação desse estudo constituiu-se, sobretudo, a partir de inquietaçóes sobre o processo educacional do aluno surdo e levando-se em conta o tempo hábil para a realização do mesmo, optou-se por contemplar a produção acadêmica segundo o ASSUNTO Educação de surdos e ANO BASE 2005 a 2009. Ressalva-se que os descritores Surdez, Inclusão de surdos, Lingua Brasileira de Sinais (LIBRAS) e Identidade surda, compreendiam campos de investigação diversificados, abarcando além do âmbito educacional, como por exemplo, áreas relacionadas às Ciências Médicas, Fonoaudiologia e Psicologia.

Os dados foram coletados por meio das informaçóes bibliográficas e dos resumos das produçóes acadêmicas, mediante fichas de catalogação. A catalogação dos dados visou mapear, identificar e/ou localizar o campo do conhecimento através dos indicadores: ano, modalidade, órgãos de fomento, estados brasileiros, universidades e programas de pós-graduação stricto sensu. 
Os dados catalogados foram organizados em tabelas e submetidos à análise de abordagem quantitativa (VILELAS, 2009), verificando-se sua distribuição e frequência segundo o respectivo indicador e o recorte temporal (2005 a 2009) e estabelecendo-se relaçóes entre as variáveis, para a elaboração de instrumentos como gráficos e quadros, utilizando-se o programa de planilha eletrônica Microsoft Excel.

\section{Resultados E Discussão}

O levantamento da produção acadêmica segundo o descritor de busca e o recorte temporal selecionados no presente estudo totalizou 224 produçóes acadêmicas, contudo, após a leitura dos resumos constatou-se que 18 produçóes não se relacionavam com a temática educação de surdos, mas referiam-se a temáticas específicas como cegueira e surdocegueira, resultando, portanto, em 206 produçóes acadêmicas consideradas nesse estudo.

\subsection{Ano e Modalidade}

O gráfico 1 apresenta a distribuição anual e por modalidade da produção acadêmica segundo o ASSUNTO Educação de surdos e ANO BASE 2005 a 2009 (Banco de Teses da CAPES 2011).

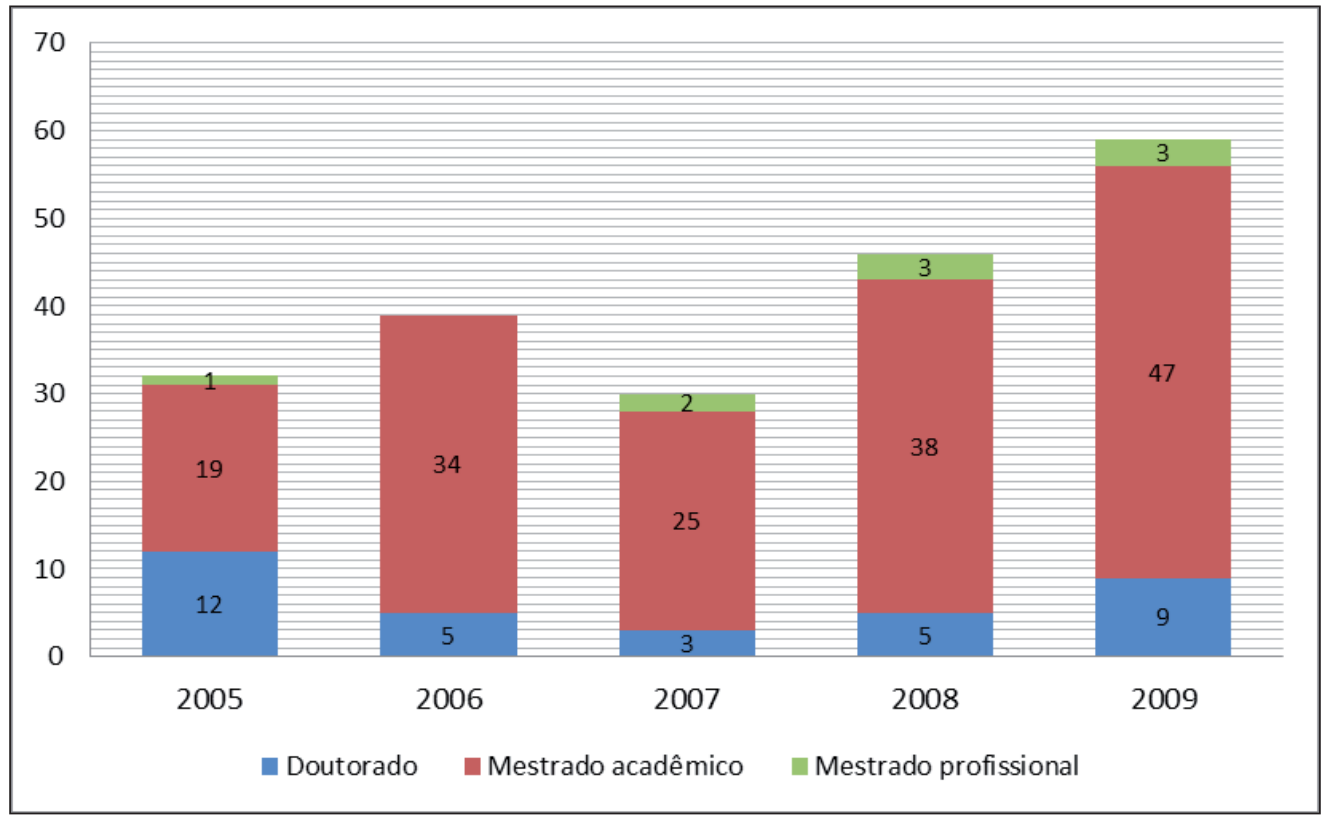

Gráfico 1- Distribuição anual e por modalidade da produção acadêmica Fonte: Elaboração dos autores.

Observa-se, exceto ao ano de 2007, gradativo aumento no número de produçóes acadêmicas na área segundo o recorte especificado. Macedo e Sousa (2010), ao traçarem um 
panorama geral do sistema de pós-graduação em Educação no país, referente ao período de 1965 a 2008, corroboram essa tendência. Segundo as autoras, o crescimento no número de mestrados e doutorados tem sido constante, com momentos de maior gradiente de expansão.

Verifica-se também, prevalência de trabalhos na modalidade mestrado acadêmico, representando 79,1\% do total de produçóes acadêmicas no período, como apresentado no gráfico 2. As modalidades doutorado e mestrado profissional representam, respectivamente, $16,5 \%$ e 4,4\% do total de produçóes acadêmicas no período.

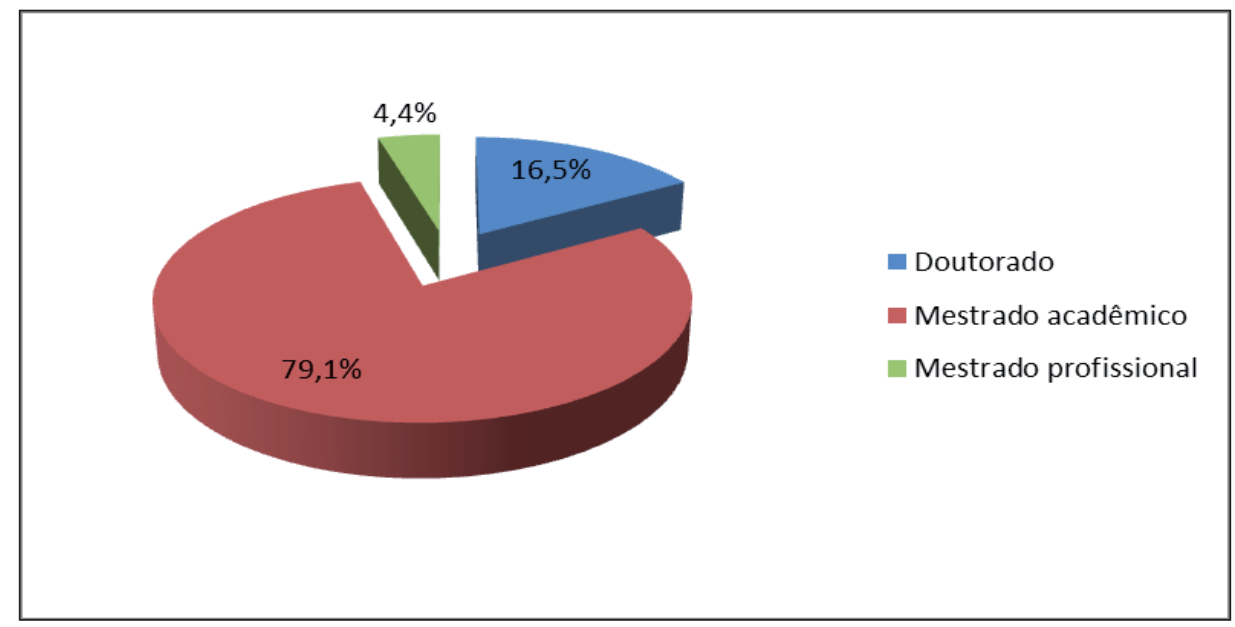

Gráfico 2 - Distribuição por modalidade da produção acadêmica Fonte: Elaboração dos autores.

Bueno (2008), ao analisar a produção acadêmica, constante no Banco de Teses da CAPES, segundo os descritores inclusão escolar e educação inclusiva no período de 1997 a 2003, apresenta índices equivalentes aos observados nesse estudo acerca da distribuição da produção segundo as modalidades mestrado e doutorado. De acordo com o autor, do total de 127 produçóes acadêmicas analisadas, 85,83\% corresponderam à modalidade mestrado e 14,17\% corresponderam à modalidade doutorado.

Ressalta-se, contudo, que o número de matrículas em cursos de mestrado acadêmico é significativamente maior do que em cursos de doutorado ou mestrado profissional. De acordo com a base de dados estatísticos GEOCAPES (CAPES, 2012a), nos anos de 2005 a 2009, o número de matrículas na modalidade mestrado acadêmico correspondeu a 418.522, na modalidade doutorado correspondeu a 250.848 e na modalidade mestrado profissional correspondeu a 39.945. Desse modo, é possível estabelecer uma correlação entre a proporção de produçóes acadêmicas e de discentes, nas respectivas modalidades.

\subsection{Regióes, Universidades e Programas de Pós-graduaÇão}

O gráfico 3 apresenta a distribuição nacional da produção acadêmica segundo o ASSUNTO Educação de surdos e ANO BASE 2005 a 2009 (Banco de Teses da CAPES 2011). 


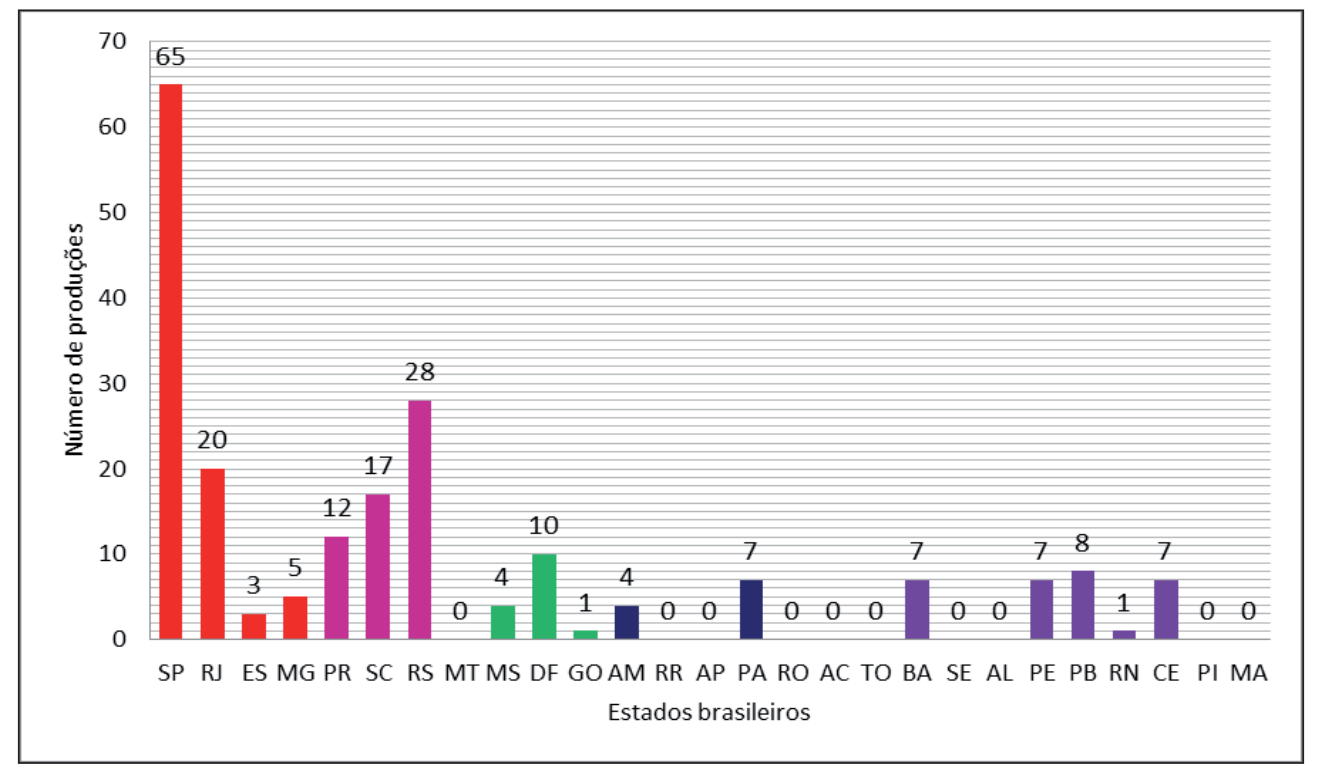

Gráfico 3 - Distribuição nacional da produção acadêmica

Fonte: Elaboração dos autores.

Observa-se a distribuição da produção acadêmica entre 17 estados brasileiros: São Paulo (SP), Rio de Janeiro (RJ), Espírito Santo (ES), Minas Gerais (MG), Paraná (PR), Santa Catarina (SC), Rio Grande do Sul (RS), Mato Grosso do Sul (MS), Distrito Federal (DF), Goiás (GO), Amazonas (AM), Pará (PA), Paraíba (PB), Rio Grande do Norte (RN), Ceará (CE), Bahia (BA) e Pernambuco (PE).

Nota-se prevalência de produção na região Sudeste, somando 93 produçôes $(45,14 \%)$ do total de 206 produçóes, com destaque para o estado de Sáo Paulo com 65 produçóes e estado do Rio de Janeiro com 20 produções. A regiāo Sul corresponde a 57 produções $(27,66 \%)$, com destaque para o estado do Rio Grande do Sul com 28 produçóes e o estado de Santa Catarina com 17 produçóes. A regiáo Centro-Oeste corresponde a 15 produçóes $(7,28 \%)$, com destaque para o Distrito Federal com 10 produçóes. A regiáo Norte corresponde a 11 produçóes (5,33\%), com o estado do Amazonas com quatro produçóes e o estado do Pará com sete produçóes. A regiáo Nordeste corresponde a 30 produçóes (14,56\%), com destaque para o estado da Paraíba com oito produçóes.

Verifica-se que as regiôes Sudeste e Sul correspondem a 72,8\% do total de produçóes acadêmicas identificadas no período. Marin, Bueno e Sampaio (2005), ao analisarem as principais tendências de investigação das produçôes acadêmicas defendidas nos programas de pós-graduação em Educação no Brasil, no período de 1981 a 1998, segundo a temática escola básica contemporânea, constataram a alta concentraçáo de produção no eixo Sudeste-Sul. Segundo os autores, "[...] grande parte dessa situação deve-se à longevidade da maioria dos 
programas, mas o fato de se situarem nas duas regióes de maior desenvolvimento do país não pode ser desprezado." (MARIN; BUENO; SAMPAIO, 2005, p.179).

Esse dado é corroborado por Ventorim (2005) ao analisar a produção científica dos Encontros Nacionais de Didática e Prática de Ensino (ENDIPES) acerca da temática formação do professor pesquisador referente ao período de 1994 a 2000. De acordo com a autora, as regióes Sudeste e Sul corresponderam a 92,67\% dos trabalhos sobre o professor pesquisador.

Os resultados observados nesse estudo, bem como, nos estudos de Marin, Bueno e Sampaio (2005) e Ventorim (2005), exprimem as assimetrias regionais, intra-regionais e entre estados do sistema de pós-graduação brasileiro.

Santos e Azevedo (2009), ao analisarem a trajetória da pós-graduação brasileira, evidenciam as assimetrias regionais na distribuição de programas e cursos de pós-graduação stricto sensu no país. Segundo as autoras, no ano de 2008 havia 3.859 cursos de mestrado (acadêmico e profissional) e doutorado, dos quais 2.093 localizavam-se na regiâo Sudeste; 754 na região Sul; 612 na região Nordeste; 256 na região Centro-Oeste; e 144 na regiáo Norte.

As considerações do V Plano Nacional de Pós-graduação (V PNPG), apresentadas pelas autoras, corroboram e complementam esses índices. Segundo o V PNPG (2005-2010),

O sistema continua concentrado na região sudeste. Independentemente de políticas direcionadas, nos últimos anos a Regiáo Sul vem encontrando estratégias desenvolvimentistas e consolidando seus programas, de sorte a ocupar hoje lugar de visibilidade no sistema. O Nordeste alcançou algum destaque, porém ainda apresenta assimetrias entre seus estados. No CentroOeste, o quadro de assimetrias é ainda mais acentuado, uma vez que a pós-graduaçáo concentra-se em Brasília. E, no Norte, região de extrema importância nacional pela sua dimensão e diversidade, encontra-se uma pós-graduação incipiente, com concentração em dois estados de uma regiáo de dimensão continental. (BRASIL, 2004, p.46).

De acordo com o documento, há necessidade de projetar estratégias para a continuidade de ampliação quantitativa e qualitativa do sistema nacional de pós-graduação, "[...] incorporando modificaçóes conceituais e organizacionais que atenuem as desigualdades regionais, intra-regionais e entre estados, bem como, as assimetrias entre áreas do conhecimento." (BRASIL, 2004, p.48).

A partir do quadro 1, observa-se a distribuição da produção acadêmica segundo os Estados, as universidades brasileiras e os respectivos programas.

\begin{tabular}{|c|c|c|}
\hline \multirow[t]{5}{*}{ Estado } & Universidade & Programa (número de produçôes) \\
\hline & USP & $\begin{array}{l}\text { Educação (4) } \\
\text { Psicologia experimental (2) } \\
\text { Psicologia (1) } \\
\text { Enfermagem psiquiátrica (1) } \\
\text { Psicologia escolar e do desenvolvimento humano (1) }\end{array}$ \\
\hline & UNESP & $\begin{array}{l}\text { Educaçáo (1) } \\
\text { Educação escolar (1) } \\
\text { Ciência da informaçăo (1) }\end{array}$ \\
\hline & UNICAMP & $\begin{array}{l}\text { Linguística Aplicada (6) } \\
\text { Educaçāo (2) } \\
\text { Linguística (1) } \\
\end{array}$ \\
\hline & UNIFESP & Distúrbios da comunicaçáo humana (1) \\
\hline
\end{tabular}




\begin{tabular}{|c|c|c|}
\hline \multirow{14}{*}{ SP } & UFSCAR & Educaçāo Especial (8) \\
\hline & ITA & Engenharia eletrônica e computaçăo (1) \\
\hline & $P U C-S P$ & $\begin{array}{l}\text { Fonoaudiologia (4) } \\
\text { Linguística aplicada e estudos da linguagem (4) } \\
\text { Educaçáa: história, política, sociedade (2) } \\
\text { Tecnologia da inteligência e design digital (1) } \\
\text { Educaçấo (1) }\end{array}$ \\
\hline & PUC-CAMP & Educação (1) \\
\hline & UNIMEP & Educaçáo (4) \\
\hline & \begin{tabular}{|l} 
MACKEN- \\
$Z I E$ \\
\end{tabular} & Distúrbios do desenvolvimento (1) \\
\hline & $U B C$ & Semiótica, tecnologia da informação e educação (1) \\
\hline & UNISO & Educação (2) \\
\hline & UMESP & Educaçáo (1) \\
\hline & CUML & Educaçáo (8) \\
\hline & USM & Educação: Administração e comunicação (1) \\
\hline & USF & Educação (1) \\
\hline & \begin{tabular}{|l|} 
UNISAL \\
\end{tabular} & Educaçáo (1) \\
\hline & UNITAU & Gestão e desenvolvimento regional (1) \\
\hline \multirow{8}{*}{ RJ } & UERJ & \begin{tabular}{|l|} 
Educaçăo (2) \\
Letras (1) \\
Psicologia social (1) \\
\end{tabular} \\
\hline & \begin{tabular}{|l|l|} 
CEFET \\
\end{tabular} & Ensino de ciências e matemática (2) \\
\hline & UFF & Educaçāo (1) \\
\hline & UFRJ & $\begin{array}{l}\text { Linguística (2) } \\
\text { Informática (1) } \\
\end{array}$ \\
\hline & $P U C-R J$ & \begin{tabular}{|l} 
Design (3) \\
Educaçáo (2) \\
\end{tabular} \\
\hline & UVA & Fonoaudiologia (2) \\
\hline & UNESA & Educaçáo (1) \\
\hline & UNIPLI & Ensino de ciências da saúde e do meio ambiente (2) \\
\hline ES & UFES & Educação (3) \\
\hline \multirow{4}{*}{ MG } & UFU & \begin{tabular}{|l|} 
Educaçáa (1) \\
História (1) \\
\end{tabular} \\
\hline & PUC-MG & Educaçáo (1) \\
\hline & CES/JF & Letras (1) \\
\hline & UNINCOR & Letras (1) \\
\hline \multirow{5}{*}{ PR } & UEM & $\begin{array}{l}\text { Educaçáo para ciência e o ensino da matemática (3) } \\
\text { Educaçâo (1) } \\
\text { Letras (1) } \\
\end{array}$ \\
\hline & \begin{tabular}{|l|l} 
UEL \\
\end{tabular} & Educação (1) \\
\hline & UFPR & \begin{tabular}{|l|} 
Educação (2) \\
Letras (1) \\
\end{tabular} \\
\hline & UNIOESTE & Letras: linguagem e sociedade (1) \\
\hline & UTP & \begin{tabular}{|l|} 
Educaçãa (1) \\
Distúrbios da comunicaçáo (1) \\
\end{tabular} \\
\hline \multirow[t]{3}{*}{ SC } & UFSC & \begin{tabular}{|l|} 
Educação (15) \\
Linguística (1) \\
Sociologia política (1) \\
\end{tabular} \\
\hline & UFRS & \begin{tabular}{|l|} 
Educaçáo (6) \\
Informática da educaçăo (1)
\end{tabular} \\
\hline & UFPEL & Educaçăo (2) \\
\hline
\end{tabular}




\begin{tabular}{|c|c|c|}
\hline \multirow{8}{*}{ RS } & UFSM & Educaçâao (5) \\
\hline & $U P F$ & Educação (1) \\
\hline & $P U C-R S$ & $\begin{array}{l}\text { Linguística e Letras (1) } \\
\text { Ciência da computação (1) } \\
\end{array}$ \\
\hline & UNISINOS & $\begin{array}{l}\text { Linguística aplicada (2) } \\
\text { Educação (1) }\end{array}$ \\
\hline & UNIFRA & Ensino de física e matemática (1) \\
\hline & $U L B R A$ & $\begin{array}{l}\text { Ensino de ciências e matemática (3) } \\
\text { Educação (1) }\end{array}$ \\
\hline & UNISC & Letras (1) \\
\hline & UNILASALLE & Educaçâao (2) \\
\hline \multirow[t]{2}{*}{ MS } & UFMS & Educaçẫo (3) \\
\hline & $U C D B$ & Educação (1) \\
\hline DF & UNB & $\begin{array}{l}\text { Educação (3) } \\
\text { Linguística aplicada (3) } \\
\text { Linguística (2) } \\
\text { Psicologia (1) } \\
\text { Ensino de ciências (1) }\end{array}$ \\
\hline GO & PUC-GO & Educaçāo (1) \\
\hline AM & UFAM & Educaçāo (4) \\
\hline \multirow[b]{2}{*}{ PA } & UEPA & Educação (1) \\
\hline & UFPA & $\begin{array}{l}\text { Educação em ciências e matemáticas (4) } \\
\text { Psicologia (1) } \\
\text { Letras: Linguística e Teoria literária (1) }\end{array}$ \\
\hline \multirow[t]{2}{*}{ PB } & UFPB & $\begin{array}{l}\text { Educação (3) } \\
\text { Letras (2) } \\
\text { Linguística (2) } \\
\end{array}$ \\
\hline & UFCG & Linguagem e ensino (1) \\
\hline RN & UFRN & Educação (1) \\
\hline \multirow{3}{*}{ CE } & UECE & Linguística aplicada (3) \\
\hline & UFC & $\begin{array}{l}\text { Educação (1) } \\
\text { Linguística (1) } \\
\text { Psicologia (1) } \\
\end{array}$ \\
\hline & UNIFOR & Saúde coletiva (1) \\
\hline \multirow[t]{2}{*}{ BA } & UNEB & \begin{tabular}{|l|} 
Educação e contemporaneidade (2) \\
\end{tabular} \\
\hline & UFBA & Educaçấo (5) \\
\hline \multirow[t]{2}{*}{ PE } & UFPE & $\begin{array}{l}\text { Educação (3) } \\
\text { Letras (1) } \\
\text { Psicologia (1) } \\
\end{array}$ \\
\hline & UNICAP & Ciências da linguagem (2) \\
\hline
\end{tabular}

Quadro 1 - Distribuição da produção acadêmica segundo os Estados, as universidades brasileiras e os respectivos programas

Notas: O número de produçóes acadêmicas correspondente à USP e à UNESP refere-se aos trabalhos produzidos em todos os seus diferentes campi. As instituiçōes privadas estão destacadas em itálico.

Fonte: Elaboração dos autores.

Destaca-se um percentual significativo de instituiçôes privadas (49,43\%) identificadas no período. Esse dado contesta os resultados apresentados no estudo realizado por Marin, Bueno e Sampaio (2005), no qual, no cômputo geral, havia 32 universidades públicas $(84,21 \%)$ e 
somente seis universidades privadas (15,79\%), no período de 1981 a 1998, segundo a temática escola básica contemporânea.

Os resultados observados no presente estudo refletem o significativo crescimento da pós-graduação stricto sensu no setor privado, em especial, com a criação de novos cursos de Mestrado, como demonstraram Macedo e Sousa (2010).

De acordo com Saviani (2000), a partir do final da década de 1980 verifica-se uma expressiva propagação de universidades privadas no país. Segundo o autor,

A impressão que se tem é que, com a consagração da autonomia universitária como princípio constitucional operada pela Constituição Federal promulgada em 05 de outubro de 1988, houve uma corrida das instituiçōes superiores privadas para se transformarem em universidades. [...] Além disso, o acirramento da concorrência e a busca de uma imagem favorável no mercado de serviços, são fatores que têm levado essas universidades privadas à iniciativa de criar, em seu âmbito, o nível de mestrado. (SAVIANI, 2000, p.10).

Todavia, observa-se que as instituiçóes privadas, identificadas no presente estudo, representam 33\% do total de produçóes acadêmicas, ratificando a predominância de produção nas universidades públicas.

Dentre as universidades apresentadas no quadro 1, evidencia-se a UFSC com 17 produçóes acadêmicas, a PUC-SP com 12 produçóes acadêmicas e a UNB com 10 produçóes acadêmicas, como as universidades com maior número de produçóes acadêmicas na área no período especificado, o que denota a relevância de tais instituições na produção de conhecimento nesse campo de investigação.

Referente aos programas de pós-graduação stricto sensu, observa-se prevalência de programas em Educação, totalizando 48 programas, os quais correspondem a 122 produçóes acadêmicas. Destacam-se os programas de Educação da UFSC com 15 produçóes; do CUML com oito produçóes; da UFRS com seis produçóes; da UFSM e da UFBA com cinco produçóes cada e da USP, da UNIMEP e da UFAM com quatro produçóes cada. Destaca-se também, o programa de Educação Especial da UFSCar com oito produçóes acadêmicas. Esse dado corrobora o papel desse campo de investigação na produção de pesquisas em educação de surdos, bem como, demonstra a representatividade do referido programa no campo.

Em seguida, evidenciam-se os programas em Letras e Linguística, totalizando 22 programas, os quais correspondem a 39 produçóes, com destaque para o programa de Linguística aplicada da UNICAMP com seis produções e o programa de Linguística aplicada e estudos da linguagem da PUC-SP com quatro produções.

Considerando-se os aspectos mais frequentemente estudados sobre a temática educação de surdos, especialmente nas últimas décadas, como a prática pedagógica, aquisição de linguagem e letramento, conforme observado no estudo desenvolvido por Nunes, Braun e Walter (2011), ratifica-se a predominância de produções acadêmicas em programas de pósgraduação stricto sensu em Educação, Letras e Linguística.

Ressalta-se, contudo, a presença de programas em Ciência da computação, Engenharia e Tecnologia, comumente observados em diferentes áreas de investigação. 
Essa análise obedeceu à classificação das Áreas do Conhecimento estabelecida pela CAPES. A classificação das Áreas do Conhecimento tem finalidade operacional, visando proporcionar aos órgãos que atuam em ciência e tecnologia uma maneira ágil e funcional de agregar suas informaçóes (CAPES, 2012b).

\subsection{FinanCiamento}

O gráfico 4 apresenta o financiamento anual segundo os órgãos de fomento da produção acadêmica.

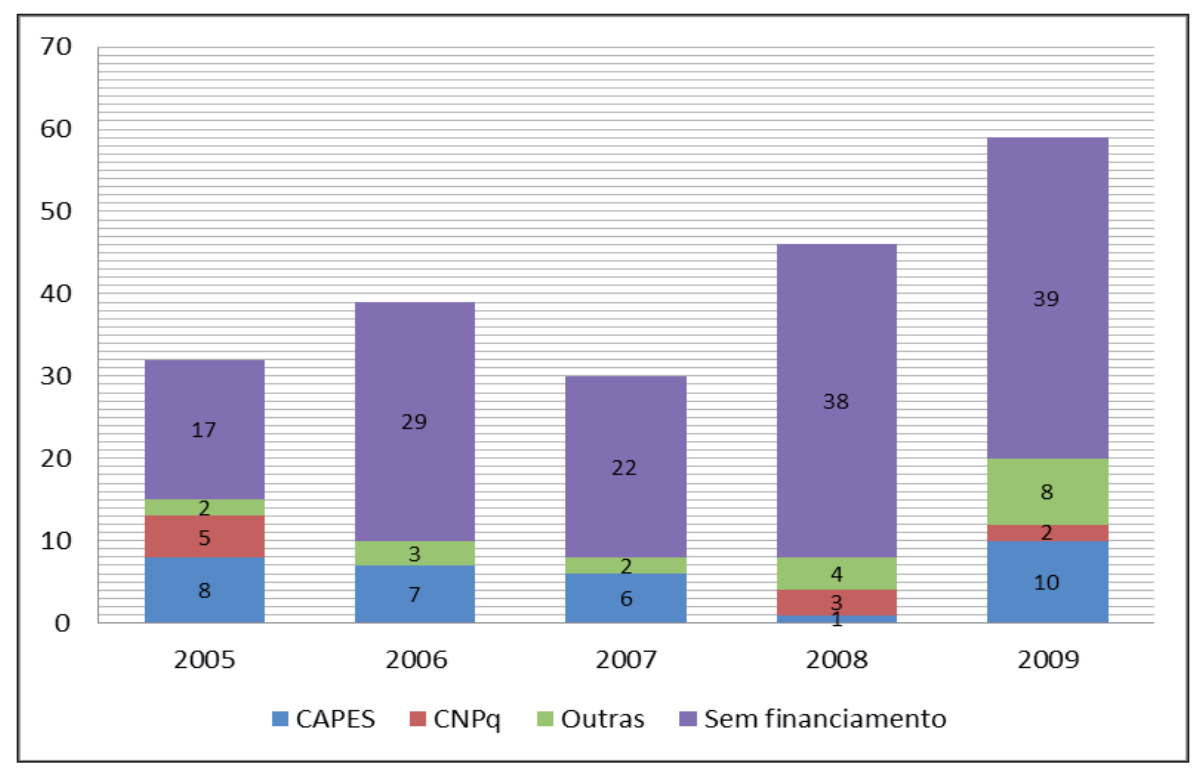

Gráfico 4- Financiamento anual e segundo os órgãos de fomento da produção acadêmica Fonte: Elaboração dos autores.

Verifica-se que $70,39 \%$ da produção acadêmica no período não possuíram financiamento. Nota-se que a CAPES corresponde ao financiamento de 15,53\% da produção acadêmica, o CNPq corresponde ao financiamento de 4,85\% e outras instâncias de fomento (Mackpesquisa (uma); FAPEAM (uma); Bolsa Mestrado SE/SP (três); PUC/SP (três); FUNCAP (uma); UNESP (uma); SEESP (duas); Governo do Estado de São Paulo (uma); UTP (uma); PUC-Rio (duas); Fundação Comunitária Tricordiana de Educação (uma); UNISINOS (uma); Santander (uma)) correspondem ao financiamento de 9,22\% da produção acadêmica.

De acordo com André (2001), observa-se, nos últimos anos, expressiva redução do financiamento da pesquisa em Educação no Brasil. De acordo com a autora, se na década de 80 a Financiadora de Estudos e Projetos (FINEP) e o Instituto Nacional de Pesquisas Educacionais (INEP) ofereciam apoio às pesquisas em Educação no país, nos últimos anos esse apoio foi quase extinto. Mesmo considerando-se as agências de fomento estaduais, deve-se 
ponderar que o número de pesquisadores qualificados para solicitar financiamento aumentou significativamente.

Ressalta-se que o financiamento da produção científica no Brasil é realizado, principalmente, por meio de quatro agências federais: o CNPq e a FINEP - subordinados ao Ministério de Ciência e Tecnologia (MCT), e o INEP e a CAPES - vinculados ao Ministério da Educação (MEC). Têm-se ainda as agências de fomento estaduais, como as Fundaçóes e Entidades de Amparo à Pesquisa (FAPs), e as agências internacionais.

Campos e Fávero (1994), em um estudo realizado acerca da pesquisa educacional no Brasil na década de 90, constataram que em 1991, do total de 3.359 alunos matriculados em programas de mestrado e doutorado em Educação, apenas 29\% recebiam bolsa de estudo concedida pela CAPES e 17\% recebiam bolsa de estudo concedida pelo CNPq. Tais dados evidenciam que, neste período, o financiamento da pesquisa em Educação no Brasil, através da concessão de bolsas de estudo, apresentava-se escasso, dado que a maior parte dos alunos matriculados em programas de Mestrado e Doutorado em Educação não contava com apoio financeiro.

Como ratificam os autores, o CNPq e a FINEP sofreram, neste período, o impacto da crise econômica do país, bem como, da contenção de despesas por parte do governo federal, causando grandes perdas em linhas de fomento.

No rastro desta discussão, Chaves (2007), ao analisar os reflexos da reforma ${ }^{4}$ implementada no Estado brasileiro, a partir da década de 1990, por meio da adoção de políticas de ajuste fiscal como estratégia para superação da crise da economia capitalista, no financiamento da produção científica no país, evidenciou uma profunda transformação no sistema brasileiro de produção científica e tecnológica, cuja reorientação central foi pautada pela promoção de parcerias entre as instituições públicas e o setor privado.

Desse modo, segundo a autora, as parcerias entre o setor público, representado pelas agências de fomento estatais e as universidades públicas, e o setor privado, através da constituição de fundos privados, passou a ser central na definição da Política Nacional para a Ciência, Tecnologia e Inovação (PNCT\&I) no país. A criação dos Fundos Setoriais de Ciência e Tecnologia 5 , no ano de 1999, constituiu-se no marco inicial da adoção da política de parceria público-privada.

O estudo, que compreendeu o período de 2000 a 2005, demonstrou que o total de recursos da Uniáo destinados à Ciência e Tecnologia (C\&T), no período supracitado, representou apenas $0,15 \%$ do $\mathrm{PIB}$, enquanto que em países como Japão, Estados Unidos, França e Alemanha, os investimentos em C\&T excederam 2,5\% do PIB. Nesta perspectiva, a

\footnotetext{
${ }^{4}$ De acordo com Chaves (2007), essa reforma fundamenta-se no argumento neoliberal da ineficácia dos serviços públicos e da necessidade da redução da participação do Estado no financiamento das políticas sociais, com a transferência de funçôes específicas para o mercado.

${ }^{5}$ Os Fundos Setoriais de Ciência e Tecnologia, criados a partir de 1999, são instrumentos de financiamento de projetos de pesquisa, desenvolvimento e inovação no país. Os Fundos Setoriais têm se constituído no principal instrumento do Governo Federal para alavancar o sistema de CT\&I nacional, possibilitando a implantaçẫo de novos projetos em ICTs, que objetivam não somente a geração de conhecimento, mas também sua transferência para empresas. Os setores privilegiados pelos Fundos Setoriais são: CTAero; CT-Agro; CT-Amazônia; CT-Aquaviário; CT-Biotec; CT-Energ; CT-Espacial; CT-Hidro; CT-Info; CT-Infra; CT-Mineral; CT-Petro, CT-Saúde; CT-Transporte; FSA-Audiovisual; Funttel e Verde-Amarelo (BRASIL, 2012).
} 
autora conclui que a política de C\&T executada pelo governo federal tem se caracterizado pela insuficiência de recursos públicos destinados ao seu financiamento (CHAVES, 2007).

Ressalta-se contudo, de acordo com a base de dados estatísticos GEOCAPES (CAPES, 2012a), que no período de 2005 a 2009 houve significativa ampliação na concessão de bolsas de pós-graduação pela CAPES, com aumento de 899 a 9.126 bolsas em 2005 para 1.757 a 12.277 bolsas em 2009. Naquele quinquênio, a Grande Área: Ciências Humanas recebeu o maior número de bolsas de pós-graduação concedidas por esse órgão de fomento.

No entanto, embora se verifique a ampliação de investimentos públicos, por meio da concessão de bolsas de pós-graduação, destinados, sobretudo, à Grande Área: Ciências Humanas no período especificado, evidencia-se a escassez de financiamento em C\&T no país, assim como observado a partir dos resultados do presente estudo, bem como, dos estudos desenvolvidos por André (2001), Campos e Fávero (1994) e Chaves (2007).

\section{Conclusóes}

A partir da constatação, no decorrer do levantamento bibliográfico, do número extremamente significativo de produções acadêmicas que versavam sobre a temática educação de surdos, o presente estudo objetivou apresentar algumas tendências e perspectivas dessa produção, considerando-se as teses e dissertações constantes no Banco de Teses da CAPES segundo o ASSUNTO Educação de surdos e ANO BASE 2005 a 2009, mapeando o respectivo campo do conhecimento segundo os indicadores: ano, modalidade, órgãos de fomento, estados brasileiros, universidades e programas de pós-graduação stricto sensu.

Desse modo, foi possível delinear um panorama do referido campo, contudo, vale ressaltar o caráter preliminar e as limitaçóes desse estudo, uma vez que compreendeu somente um determinado período e contemplou apenas alguns aspectos da produção. Destarte, evidencia-se a necessidade de prosseguir e aprofundar esta investigação, no sentido de identificar os temas relevantes, emergentes e recorrentes, os referenciais teóricos, a natureza metodológica e os resultados observados nos estudos, com vistas a constituir tendências e perspectivas.

Pode-se afirmar que os resultados observados corroboraram os apontamentos de alguns estudos que focalizaram semelhantes aspectos, como o crescimento constante no número de Mestrados e Doutorados no país; a prevalência de produçóes na modalidade Mestrado acadêmico; a distribuição geográfica e institucional dos estudos concentrada no eixo SudesteSul; e a insuficiência de aportes financeiros, por meio da concessão de bolsas por agências de fomento, destinados à produção científica.

Foi possível observar ainda, a relevância de determinadas universidades na produção de conhecimento nesse campo de investigação, como a Universidade Federal de Santa Catarina (UFSC), a Pontifícia Universidade Católica de São Paulo (PUC-SP) e a Universidade de Brasília (UNB), bem como, o percentual expressivo de instituiçôes privadas, embora segundo o número de produçóes acadêmicas as universidades públicas sejam predominantes. Esse cenário suscita, portanto, a seguinte indagação: quais os fatores políticos, econômicos e educacionais que subjazem a esta demanda? 
Constatou-se ainda, a predominância de produçóes acadêmicas em programas de pós-graduação em Educação, Letras e Linguística como esperado a priori, todavia, a presença de programas comumente observados em diferentes áreas de investigação, como programas em Ciência da computação, Engenharia e Tecnologia, exprime que o objeto de estudo educação de surdos pode estar relacionado a diferentes prismas de investigação.

Por fim, evidencia-se a relevância de estudos que visem sistematizar e inventariar a produção acadêmico-científica em um determinado campo do conhecimento, no sentido de delinear um panorama do respectivo campo, fornecer subsídios às investigaçóes ulteriores e contribuir para o aprimoramento do campo de investigação.

\section{REFERÊNCIAS}

ANDRÉ, M. Pesquisa em educação: buscando rigor e qualidade. Cadernos de Pesquisa, São Paulo, n. 113, p. 51-64, jul. 2001. Disponível em: <http://www.scielo.br/pdf/cp/n113/a03n113.pdf>. Acesso em: 10 maio 2012.

BRASIL. Ministério da Ciência, Tecnologia e Inovação. Financiadora de Estudos e Projetos. 2012. Disponível em: <http://www.finep.gov.br/fundos_setoriais/fundos_setoriais_ini. asp?codSessaoFundos=1>. Acesso em: 19 jun. 2012.

. Ministério da Educação. Coordenação de Aperfeiçoamento de Pessoal de Nível Superior. Plano Nacional de Pós-Graduação 2005-2010. 2004. Brasília, DF: MEC/CAPES, 2004. Disponível em: <http://www.capes.gov.br/images/stories/download/editais/PNPG_2005_2010.pdf>. Acesso em: 21 mar. 2012.

BUENO, J. G. S. A produção acadêmica sobre inclusão escolar e educação inclusiva. In: MENDES, E. G.; ALMEIDA, M. A.; HAYASHI, M. C. P. I. (Org.). Temas em educação especial: conhecimentos para fundamentar a prática. Araraquara: Junqueira\&Marin; Brasília, DF: CAPES-PROESP, 2008. p. 31-47. . A produção acadêmica sobre a inclusão escolar e educação inclusiva. In: CONGRESSO BRASILEIRO DE EDUCAÇÃO ESPECIAL, 2., 2005. São Carlos. Livro de Programa e Resumos. São Carlos: UFSCar, 2005. Não paginado.

CAMPOS, M. M.; FÁVERO, O. A pesquisa em educação no Brasil. Cadernos de Pesquisa, São Paulo, n. 88, p. 5-17, fev. 1994. Disponível em: <http://educa.fcc.org.br/pdf/cp/n88/n88a01.pdf>. Acesso em: 6 jan. 2013.

CHAVES, V. L. J. Política de financiamento da pesquisa no Brasil e no Pará. In: REUNIÃO ANUAL DA ANPED, 30., 2007. Caxambu. Trabalhos GT11 - Política de Educação Superior. Caxambu, 2007. Disponível em: <http://30reuniao.anped.org.br/trabalhos/GT11-3112--Int.pdf>. Acesso em: 10 jun. 2012.

COORDENAÇÃO DE APERFEIÇOAMENTO DE PESSOAL DE NÍVEL SUPERIOR [CAPES]. GEOCAPES Dados Estatísticos. 2012a. Disponível em: <http://geocapes.capes.gov.br/ geocapesds $/ \#$ app=c501\&da7a-selectedIndex=0\&5317-selectedIndex=0\&dbcb-selectedIndex $=0>$. Acesso em: 17 ago. 2012a.

. Tabela de áreas de conhecimento. 2012b. Disponível em: <http://www.capes.gov.br/images/ stories/download/avaliacao/TabelaAreasConhecimento_072012.pdf>. Acesso em: 15 ago. 2012b. 
FERREIRA, N. S. A. As pesquisas denominadas “estado da arte”. Educação \& Sociedade, Campinas, ano XXIII, n.79, p. 257-272, ago. 2002. Disponível em: <http://www.scielo.br/pdf/es/v23n79/10857. pdf $>$. Acesso em: 10 maio 2012.

KLEIN, M.; FORMOZO, D. Im/possibilidades na educação de surdos: discussóes sobre currículo e diferença. Currículo sem Fronteiras, v.9, n.2, p.212-225, jul./dez. 2009. Disponível: <http://www. curriculosemfronteiras.org/vol9iss2articles/klein-formozo.pdf>. Acesso em: 15 maio 2012.

MACEDO, E.; SOUSA, C. P. A pesquisa em educação no Brasil. Revista Brasileira de Educaçâo, Rio de Janeiro, v.15, n.43, p.166-176, 2010.

MANZINI, E. J. Tipo de conhecimento sobre inclusão produzido pelas pesquisas. Revista Brasileira de Educação Especial, Marília, v. 17, n. 1, p. 53-70, jan./abr. 2011. Disponível em: <http://www.scielo.br/ scielo.php?pid=S1413-65382011000100005\&script=sci_arttext>. Acesso em: 10 maio 2012.

MARIN, A. J.; BUENO, J. G. S.; SAMPAIO, M. M. F. Escola como objeto de estudo nos trabalhos acadêmicos brasileiros: 1981/1998. Cadernos de Pesquisa, São Paulo, v. 35, n. 124, p. 171-199, jan./abr. 2005. Disponível em: <http://www.scielo.br/scielo.php?script=sci_arttext\&pid $=$ S0100-15742005000100009>. Acesso em: 20 jun. 2012.

NUNES, L. R. O. P.; BRAUN, P.; WALTER, C. C. F. Procedimentos e recursos de ensino para o aluno com deficiência: O que tem sido disseminado nos trabalhos do GT 15 da ANPED sobre estes temas? Revista Brasileira de Educação Especial, Marília, v. 17, nesp., p.23-40, 2011. Disponível em: <http://www.scielo.br/pdf/rbee/v17nspe1/04.pdf>. Acesso em: 15 maio 2012.

NUNES, L.R.O.P. et al. Pesquisa em Educação Especial na Pós-graduação. Rio de Janeiro: Sette Letras, 1998.

SANTOS, A. L. F.; AZEVEDO, J. M. L. A pós-graduação no Brasil, a pesquisa em educação e os estudos sobre a política educacional: os contornos da constituição de um campo acadêmico. Revista Brasileira de Educação, Rio de Janeiro, v.14, n.42, p.534-550, 2009. Disponível em: <http://www. scielo.br/pdf/rbedu/v14n42/v14n42a10.pdf>. Acesso em: 20 jun. 2012.

SAVIANI, D. A pós-graduação em educação no Brasil: trajetória, situação atual e perspectivas. Revista Diálogo Educacional, Curitiba, v.1, n.1, p.1-19, 2000. Disponível em: http://www2.pucpr.br/reol/ index.php/DIALOGO?dd1=703\&dd99=pdf. Acesso em: 6 jan. 2013.

VENTORIM, S. A Formação do professor pesquisador na produção científica dos encontros de Didática e Prática de Ensino: 1994-2000. 2005. 345 f. Tese (Doutorado em Educação) - Universidade Federal de Minas Gerais, Belo Horizonte, 2005. Disponível em: http://www.bibliotecadigital.ufmg.br/dspace/ bitstream/1843/FAEC-85EPZ5/1/silvana_ventorim.pdf. Acesso em: 19 set. 2012.

VILELAS, J. Investigação: o processo de construção do conhecimento. Lisboa: Ediçôes Sílabo Lda, 2009.

Recebido em: 12/08/2013

Reformulado em: 25/03/2014

Aprovado em: 05/05/2014 